\title{
BUDDHIST ATTITUDE TOWARDS HEALTH RELATED PHYSICAL FITNESS IN KATHMANDU VALLEY
}

\author{
Madhav Kumar Shrestha \\ Lecturer, Department of Health, Physical and Population Education, Sanothimi Campus, \\ Bhaktapur, TU. \\ Corresponding author: lunumadhav@gmail.com
}

\begin{abstract}
This study entitled "Buddhist Attitude towards Health Related Physical Fitness in Kathmandu Valley", was carried out to find out the Buddhist attitude towards health related physical fitness. The necessary information was taken from six Monasteries and Bihars of Kathmandu Valley. Altogether, there were 310 respondents for quantitative data and six respondents for qualitative data. The major source of data was primary. The researcher used attitude scale and in-depth interview for data collection. The researcher found that the health-related physical fitness is most important aspect for improving physical condition, fighting against diseases, to reduce stress and maintaining mental fitness. Similarly, it helps us to maintain the degree of health, bodily posture, physique, proper functioning of organs and good health habits along with an adequate amount of endurance, strength, stamina and flexibility. Another finding highlighted that, through meditation and walking meditation, the body achieves a greater state of balance and breathing is regulated. Our mind becomes focused, clear, and organized. Unnecessary desires and improper thoughts are eliminated. Most of the Buddhist have had positive attitude towards health related physical fitness.
\end{abstract}

Keywords: health related physical fitness - attitude - strength - endurance flexibility - agility - balance.

\section{INTRODUCTION}

Health related physical fitness is powerful means for keeping physical and mental health (Johnson \& Nelson 1988). We can obtain physical and mental health by the help of different meditation, exercise, yoga and modern games and sports. Health-related physical fitness includes strength and endurance of skeletal muscles, joint flexibility, body composition and 
cardio-respiratory endurance. All these attributes change in response to appropriate physical conditioning programs, and related to health (Baruwal 2014).

Strength and endurance of skeletal muscles of the trunk help to maintain correct posture and prevent such problems as low back pain (Budhathoki, Wagle \& Shrestha 2019). Minimal levels of muscular strength and endurance are needed for regular tasks of living, such as carrying bags of groceries, picking up child. Individuals with very low levels of muscular strength and endurance are limited in the performance of regular tasks and have to lead a restricted life (Colgan 1978). Such limitations are perhaps only indirectly related to health, but individuals who cannot pick up and hug a grandchild or must struggle to get up from a soft chair surely have a lower quality of life than that enjoyed by their fitter peers (World Health Organization 2018).

Flexibility is range of motion around the joints, also ranks as an important component of health-related fitness (Maharjan \& Adhikari 2014). Lack of flexibility in the lower back and posterior thigh is thought to contribute to low back pain. Extreme lack of flexibility also has a harmful effect on the quality of life and limiting performance (Bucher 1979).

Buddhism is the most virtuous and perfect education system which is directed by the Buddha (Yun 2007). This education covers a limitless range of phenomena and principles. Buddhism is not limited only to religion; it is truly an education of the wisdom, understanding and discipline of life. Nowadays, the terms teachers and students are only used in modern schools and universities. But teachers and students should not be limited in schools and universities. Buddha Shakyamuni is our original teacher. Buddhism is directly related to teaching, advising, disciplining and general services (Dunn 2010). Therefore, we can say Buddhism is truly an education system.

Health is wealth; therefore, we should keep both mind and body healthy and fit. The health of the person depends on physical exercise, meditation and balance diet. Physical exercise is the practice of preventing from various diseases and illness (Lee, Eric, Lobelo, Puska, \& Katzmarzyk 2012). Buddha dharma is better way to make body and mind healthy and fit. Human mind and body are interdependent, healthy body influences healthy mind and healthy mind influences healthy body. Buddha's teaching is focused on the impermanence (Anicca), suffering (Dukkha) and nonself (Anatta). His teaching also emphasizes on the importance of health (Shakya 2010). In this context famous philosopher Plato said Healthy body 
in a healthy mind. Healthy mind is able to judge, give decision, examine ourselves, clearly identify the nature of our obstacles and work to resolve them. The essence of his teaching is to bring peace and happiness in one's life (Harvey 2013). In regard to health, Buddha's said Arogyaparama lava which means health is highest gain. He also said Yogilananupatthati and upathathi, it means who attends the sick and attends on me. In monastic rules: dietary, taking medicine, cleaning the rooms, cutting nails, brushing teeth, water management, meditation etc. are mentioned for achieving good physical and mental health. He had also prescribed five precepts (Panchasila) and eight precepts (Astasila) for obtaining good physical and mental health of general people

Attitudes are ideas or feelings that may have something as a result of past experience or as a result of like and dislike (Thurstone 1928). When condition or changes in the environment occur, whether for better or worse, we can usually expect to see a change in attitude (Fishbein \& Ajzen 1975). In physical activities and sports program, we are concerned with the attitudes of students towards the physical activities or program as well as individual and group activities with the programs (Stein 2014).

Triandes (1971) also defined attitude as, "an idea charged with emotion which predisposes a class of actions to a particular class of social situations." He suggests that attitudes consist of three components: (a) a cognitive component, which is a way for humans to categorize ideas, (b) an affective component, which is the emotion that charges the idea, and (c) a behavioral component, which guides behavior.

Although the debate over the definition of attitude continues, most social psychologists acknowledge the importance of attitudes in the lives of human beings. According to Katz (1960) attitudes serve people in four ways. First, attitudes guide behaviour toward valued goals and away from aversive events. Secondly, attitudes help to manage and simplify information. Thirdly, attitudes allow people to communicate information about their personality and values. And lastly, attitudes protect people from unacceptable or threatening thoughts, urges, and impulses.

\section{OBJECTIVES OF THE STUDY}

The objectives of this study are to identify the Buddhist attitudes towards health related physical fitness and to analyze the relationship among the health related physical fitness, good health and academic performance. 


\section{METHODOLOGY}

The researcher adopted explanatory research design. The populations of this study were 310 Buddhist for quantitative data and six Buddhist for qualitative data. The Monasteries and Bihars were selected purposively; however, the respondents for the quantitative study were selected randomly. The researcher had applied Carr attitude scale for quantitative data and in-depth interview for qualitative data collection. The quantitative data were analyzed using a Statistical Package for Social Science (SPSS) version 20 from which mainly the Chi-square and percentage were used. After collecting the qualitative data, the researcher treats the various codes, relate each other statements. This is the final stage of making analytical sense of the data, creating storyline around which all other codes and categories are integrated

\section{RESULTS AND DISCUSSIONS}

Health-related physical fitness involves the components of physical fitness related to health status, including cardiovascular fitness, musculoskeletal fitness, body composition and metabolism. Physical activity and physical fitness are often used interchangeably, with fitness commonly being treated as a more accurate measure of physical activity than self-report. Physical fitness appears to be similar to physical activity in its relation to morbidity and mortality but is more strongly predictive of health outcomes than physical activity.

Table 1: Role of health related physical fitness on concentration

\begin{tabular}{ccccccc}
\hline $\begin{array}{c}\text { Scoring } \\
\text { Key }\end{array}$ & Male & Percent & Female & Percent & Total & Total \\
percent \\
\hline SA & 57 & 18.4 & 29 & 09.4 & 86 & 27.7 \\
A & 61 & 19.7 & 44 & 14.2 & 105 & 33.9 \\
U & 30 & 09.7 & 24 & 07.7 & 54 & 17.4 \\
D & 25 & 08.1 & 11 & 3.5 & 36 & 11.6 \\
SD & 14 & 04.5 & 15 & 04.8 & 29 & 09.4 \\
\hline Total & 187 & 60.3 & 123 & 39.7 & 310 & 100 \\
\hline
\end{tabular}

Table 1 shows that among 310 respondents 86 (27.7 percent) stated strongly agree, 105 (33.9 percent) expressed agree, 54 (17.4 percent) undecided, 36 (11.6 percent) disagree and 29 (09.4 percent) strongly disagree. In a positive way, 191 respondents (61.6 percent) agreed on the above statement. It can be interpreted that sports and physical activities help to get better concentration. 
Buddhists' responses were statistically analyzed; the calculated value of Chi-square was 5.015 in 95 percent level of significance and 4 degree of freedom. Cumulatively majority (61.6 percent) of respondents responded positively on the role of health related physical fitness on concentration.

These interesting responses were followed up during the face to face interviews. Some of the quoted responses are: "The physical exercise improves physical condition and immunity power and maintains mental fitness and it can reduce stress." Other respondent said: "Physical exercise is very effective at reducing fatigue, improving alertness and concentration and at enhancing overall cognitive function".

Table 2: Role of health related physical fitness to stay on healthy and fit

\begin{tabular}{|c|c|c|c|c|c|c|}
\hline \multirow[t]{2}{*}{ Scoring Key } & \multicolumn{4}{|c|}{ Sex of the Respondents } & \multirow[t]{2}{*}{ Total } & \multirow{2}{*}{$\begin{array}{l}\text { Total } \\
\text { percent }\end{array}$} \\
\hline & Male & Percent & Female & Percent & & \\
\hline SA & 63 & 20.3 & 44 & 14.2 & 107 & 34.5 \\
\hline A & 63 & 20.3 & 34 & 11.0 & 97 & 31.3 \\
\hline $\mathrm{U}$ & 18 & 05.8 & 22 & 07.1 & 40 & 12.9 \\
\hline $\mathrm{D}$ & 29 & 09.4 & 19 & 6.1 & 48 & 15.5 \\
\hline SD & 14 & 04.5 & 04 & 01.3 & 18 & 05.8 \\
\hline Total & 187 & 60.3 & 123 & 39.7 & 310 & 100 \\
\hline
\end{tabular}

Table 2 reveals that among 310 respondents 107 (34.5 percent) said strongly agree, 97 (31.3 percent) agree, 40 (12.9 percent) undecided, 48 (15.5 percent) disagree and 18 (05.8 percent) strongly disagree on the statement the role of health related physical fitness to stay healthy and fit. It can be interpreted that sports and physical activities help to get better health.

The respondents' responses were statistically analyzed, the calculated value of Chi-square was 7.176 in 95 percent level of significance and 4 degree of freedom which shows that health related physical fitness is necessary to stay healthy and fit.

Some important responses were highlighted during the face to face interviews about health related fitness helps to stay healthy and fit. One Buddhist stated, "It helps us to maintain degree of health, bodily posture, physique, proper functioning of organs, and good health habits along with an adequate amount of endurance, strength, stamina and flexibility." Other respondent said, "Health related physical fitness helps to keep healthier and a better quality of life, improved sleep, and reduced stress." 
156 BUDDHIST ATTITUDE TOWARDS HEALTH RELATED PHYSICAL ...

Table 3: Health related physical fitness and work efficiency

\begin{tabular}{|c|c|c|c|c|c|c|}
\hline \multirow{2}{*}{$\begin{array}{c}\text { Scoring } \\
\text { Key }\end{array}$} & \multicolumn{4}{|c|}{ Sex of the Respondents } & \multirow[t]{2}{*}{ Total } & \multirow{2}{*}{$\begin{array}{c}\text { Total } \\
\text { percent }\end{array}$} \\
\hline & Male & Percent & Female & Percent & & \\
\hline SA & 54 & 17.4 & 44 & 14.2 & 98 & 31.6 \\
\hline A & 58 & 18.7 & 30 & 09.7 & 88 & 28.4 \\
\hline $\mathrm{U}$ & 43 & 13.9 & 31 & 10.0 & 74 & 23.9 \\
\hline $\mathrm{D}$ & 29 & 09.4 & 09 & 02.9 & 38 & 12.3 \\
\hline SD & 03 & 01.0 & 09 & 02.9 & 12 & 03.9 \\
\hline Total & 187 & 60.3 & 123 & 39.7 & 310 & 100 \\
\hline
\end{tabular}

Table 3 shows that among 310 respondents 98 (31.6 percent) spoken strongly agree, 88 (28.4 percent) agree, 74 ( 23.9 percent) undecided, 38 (12.3 percent) disagree and 12 (03.9 percent) strongly disagree on the statement "health related physical fitness and work efficiency". It means Buddhists have positive attitude towards health related physical fitness.

When the Buddhist's responses were statistically analyzed, the calculated value of Chi-square was 12.732 which show that there is no significant difference between what was expected and the responses from the Buddhist in 95 percent level of significance and 4 degree of freedom.

The result of face to face interview, one Buddhist responded, "Physically fit persons doing daily work and other activities with the least effort possible." Another respondent said, "Yoga is the practice of integrating physical activities and movement with controlled breathing and meditation and is known to improve depressive symptoms and work efficiency."

Table 4: Health related physical fitness and academic achievement

\begin{tabular}{|c|c|c|c|c|c|c|}
\hline Scoring & \multicolumn{4}{|c|}{ Sex of the Respondents } & \multirow[t]{2}{*}{ Total } & \multirow{2}{*}{$\begin{array}{c}\text { Total } \\
\text { percent }\end{array}$} \\
\hline Key & Male & Percent & Female & Percent & & \\
\hline SA & 35 & 11.3 & 28 & 0.9 & 63 & 20.3 \\
\hline A & 79 & 25.5 & 59 & 19.0 & 138 & 44.5 \\
\hline $\mathrm{U}$ & 39 & 12.6 & 23 & 07.4 & 62 & 20.0 \\
\hline $\mathrm{D}$ & 19 & 06.1 & 06 & 01.9 & 25 & 08.1 \\
\hline $\mathrm{SD}$ & 15 & 04.8 & 07 & 02.3 & 22 & 07.1 \\
\hline Total & 187 & 60.3 & 123 & 39.7 & 310 & 100 \\
\hline
\end{tabular}

Table 4 shows that majority ( 64.8 percent) of respondents agreed on the statement of health related physical fitness helps to get better academic achievement. Where 63 (20.3 percent) respondents expressed strongly 
agree, 138 (44.5percent) agree, 62 (20 percent) undecided, 25 (08.1 percent) disagree and 22 (07.1 percent) strongly disagree on the same statement.

When the Buddhists' responses were statistically analyzed, the calculated value of Chi-square was 4.451 in 95 percent level of significance and 4 degree of freedom which shows that physical fitness is necessary to achieve academic achievement.

These interesting responses were followed up during the face to face interview. One respondent responded, "Health related physical fitness is essential for the development of mental, physical, social and spiritual aspects of individuals. Hence a well-organized and properly administered physical education program for school children is very essential. " Another respondent said, "Regular physical activity reduces the risk of coronary heart disease, diabetes, hypertension, colon cancer, breast cancer and depression. Additionally, physical activity is a key determinant of energy expenditure, and thus is fundamental to energy balance and weight control."

Table 5: Necessity of health related physical fitness

\begin{tabular}{|c|c|c|c|c|c|c|}
\hline \multirow{2}{*}{$\begin{array}{c}\text { Scoring } \\
\text { Key }\end{array}$} & \multicolumn{4}{|c|}{ Sex of the Respondents } & \multirow{2}{*}{ Total } & \multirow{2}{*}{$\begin{array}{c}\text { Total } \\
\text { percent }\end{array}$} \\
\hline & Male & Percent & Female & Percent & & \\
\hline SA & 44 & 14.2 & 37 & 11.9 & 81 & 26.1 \\
\hline $\mathrm{A}$ & 88 & 28.4 & 57 & 18.4 & 145 & 46.8 \\
\hline $\mathrm{U}$ & 18 & 05.8 & 09 & 02.9 & 27 & 08.7 \\
\hline $\mathrm{D}$ & 18 & 05.8 & 14 & 04.5 & 32 & 10.3 \\
\hline $\mathrm{SD}$ & 19 & 06.1 & 06 & 01.9 & 25 & 08.1 \\
\hline Total & 187 & 60.3 & 123 & 39.7 & 310 & 100 \\
\hline
\end{tabular}

Table 5 shows that among 310 respondents, 81 (26.1 percent) voiced strongly agree, 145 (46.8 percent) agree, 27 (08.76 percent) undecided, 32 (10.3 percent) disagree and 25 (08.1 percent) strongly disagree on the statement necessity of health related physical fitness. It can be concluded that health related physical fitness is most necessary for all.

When the Buddhist's responses were statistically analyzed, the calculated value of Chi-square was 4.470 in 95 percent level of significance and 4 degree of freedom. It shows that physical fitness is most necessary to gain better health.

Some of the respondents responses are: "Health related physical fitness provides benefits to all sexes, all ages and including persons with disabilities, with a wide range of physical, social, emotional, spiritual and 
mental health. Physical activity and sport support strategies to improve diet and discourage the use of tobacco, alcohol and drugs. As well, physical activity and sport help to reduce violence, enhance functional capacity, and promote social interaction and integration." Other respondent said: "Health related physical fitness can help people with chronic disease and other health problem, improve their stamina and muscle strength and can improve psychological well-being and quality of life and increase the ability to perform activities of daily life."

Table 6: Relationship between health and physical exercise

\begin{tabular}{ccccccc}
\hline $\begin{array}{c}\text { Scoring } \\
\text { Key }\end{array}$ & \multicolumn{4}{c}{ Sex of the Respondents } & Total & Total \\
Male & Percent & Female & Percent & & percent \\
\hline SA & 37 & 11.9 & 29 & 09.4 & 66 & 21.3 \\
A & 74 & 23.9 & 40 & 12.9 & 114 & 36.8 \\
U & 26 & 08.4 & 26 & 08.4 & 52 & 16.8 \\
D & 43 & 13.9 & 22 & 07.1 & 65 & 21.0 \\
SD & 07 & 02.3 & 06 & 01.9 & 13 & 04.2 \\
\hline Total & 187 & 60.3 & 123 & 39.7 & 310 & 100 \\
\hline
\end{tabular}

Above table represents that among 310 respondents 66 (21.3 percent) voiced strongly agree, 114 (36.84 percent) agree, 52 (16.8 percent) undecided, 65 (21 percent) disagree and 13 (04.2 percent) strongly disagree on the statement relationship between health and physical exercise.

When the Buddhist's responses were statistically analyzed, the calculated value of Chi-square 4.971 shows that there is significant difference between what was expected and the responses from the Buddhist in 5 percent level of significance and 4 degree of freedom. Most of the Buddhist have had positive attitude towards physical education and sports activities.

In face to face interview, one respondent said, "Physical activities, sports, meditation and exercises make us feel better and more relaxed and it helps to achieve high degree of health condition." Most of the Buddhist shared the same feelings about Health related physical fitness. Therefore, it can be concluded that the Buddhist have had positive attitudes towards health related physical fitness.

\section{CONCLUSIONS}

Researcher has found positive attitudes towards health related physical fitness but some barriers such as facilities and equipment, dress for participants, teachers and the learning environment are hindering 
Buddhist's participation in physical exercise and sports activities in and out of Monastery. The findings highlight that health related physical fitness helps to keep healthier and a better quality of life, improved sleep, and reduced stress. Similarly, it is essential for the development of mental, physical, social and spiritual aspects of individuals. Hence a well-organized and properly administered physical education program for people is very essential to maintain physical fitness.

\section{REFERENCES}

Baruwal, H. B. (2014). History of physical education and sports. Kathmandu: Pinnacal publication, pp 20-45.

Bucher, C. A. (1979). Foundations of physical education. London: The C.V. mosby company, pp 54-67.

Budhathoki, C. B., Wagle, B. \& Shrestha, M. (2019). Health and physical education. Kathmandu: Pinnacle Publication, pp 30-54.

Colgan S. M. (1978). A comparative study of the AAHPER youth fitness test and proposed fitness test. Completed research in health, physical education and recreation.

Dunn, J. M. (2010). Benefits of mindfulness meditation in a corrections setting. Dunn benefits of meditation in corrections setting. https:// www.upaya.org/uploads/pdfs/.pdf, Accessed: 03.04.2019.

Fishbein, M. \& Ajzen, I. (1975). Belief, attitude, intention, and behavior: An introduction to theory and research. Addison-Wesley Publication, pp 110-156.

Halloran, J. D. (1967). Attitude formation and change. Great Britain: Leicester University Press, p 57.

Harvey, P. (2013). Introduction to buddhism teaching, pistory and Practice second Edition. New york: Cambridge University Press, pp 45-89.

Johonson, B. \& Nelson. J. K. (1988). Practical measurement for evaluation in physical education. Delhi: Surjeet publication, 7- K, Kolhapur Road, pp 44-95.

Katz, D. (1960). The functional approach to the study of attitudes. Public Opinion Quarterly, 24 (3): 163-204.

Khanal, P. (2012). Policy as a practice of power: an analysis of the policy todecentralize schooleducation in Nepal. Cunterbury. (Unpublished Ph.D dissertation), Canterbury Christ Church University, UK. 
Lee, I. S., Eric J., Lobelo, F., Puska, P., \& Katzmarzyk, P. T. (2012). Effect of physical inactivity on major non-communicable diseases worldwide: an analysis of burden of disease and life expectancy. The Lancet 80 (2): 219-229.

Maharjan, R. K. \& Adhikari, P. (2014). Foundation of physical education. Kathmandu: Sunlight Publication, pp 20-56.

Ortega, F. B., Artero, E. G., Ruiz, J. R., \& Moreno, L. A. (2011). Physical fitness levels among European adolescents: the HELENA study. British Journal of Sports Medicine, 45(1): 20-29.

Ruiz, J. R., Castro-Piñero, J., España, V., Artero, E. G., \& Ortega, F. B. (2011). Field-based fitness assessment in young people: the ALPHA health-related fitness test battery for children and adolescents. British Journal of Sports Medicine, 45(6): 518-524.

Shakya, S. K. (2010). Health and hygiene in buddha's teaching. (Unpublished Master's Thesis), Central Department of Buddhist Studies, TU, Kathmandu.

Stein, S. (2014). The reliability of youth fitness test items in India. International Journal of Epidemiology, 35 (2): 328-329.

Thurstone, L. L. (1928). Attitudes can be measured. American Journal of Sociology, 33 (4): 529-554.

Triandes, H. C. (1971). Attitude and attitude change. New York: John Wiley $\&$ Sons Publication.

World Health Organization. (2010). Global recommendations on physical education for health. https:/www.who.int/publications/i/ item/9789241599979, Accessed: 23.O6.2019).

World Health Organization. (2018). Global recommendations on physical education for health. https://www.who.int/news-room/fact-sheets/ detail/physical-activity, Accessed: 05.02.2020.

Yun, V. M. (2007). Buddhism, medicine, and health Buddhism in every step 24. http://www.fgsitc.org/wp-conten, Accessed: 03.04.2018. 